Document downloaded from:

http://hdl.handle.net/10251/143314

This paper must be cited as:

Quindt, MI.; Gutiérrez, LG.; Kneeteman, MN.; Mancini, P.; Parra Alvarez, M.; Gil Grau, S.; Costero, AM. (2018). A New Highly Selective Chromogenic and Fluorogenic Chemosensor for Copper (II). Letters in Organic Chemistry. 15(8):659-664.

https://doi.org/10.2174/1570178615666180102155804

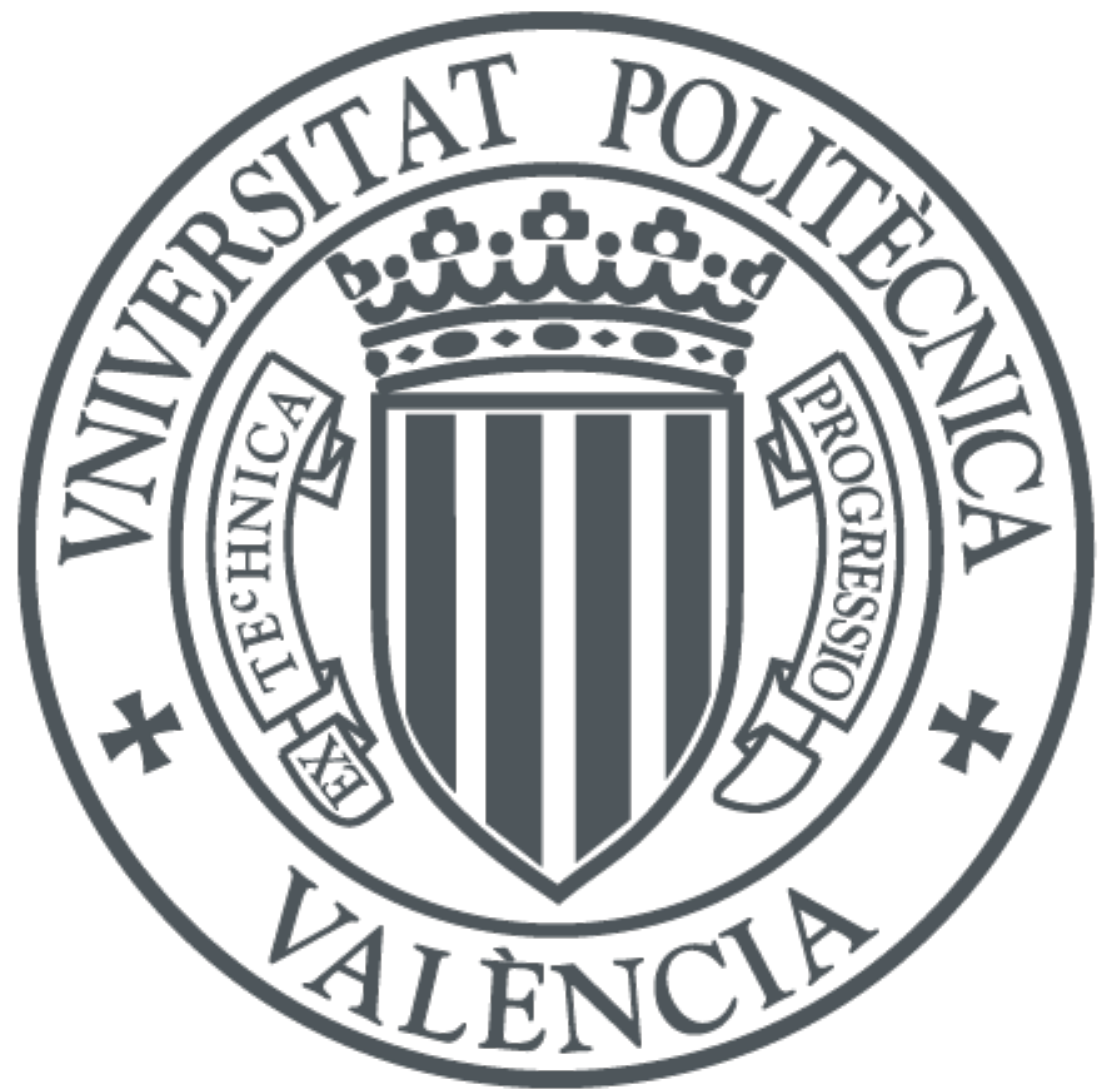

The final publication is available at

https://doi.org/10.2174/1570178615666180102155804

Copyright Bentham Science

Additional Information 


\section{A new highly selective chromogenic and fluorogenic chemosensor for Copper}

(II)

Matías I. Quindt ${ }^{\mathrm{a}}$, Leandro G. Gutierrez ${ }^{\mathrm{a}}$, María N. Kneeteman ${ }^{\mathrm{a}}{ }^{*}$, Pedro M. E. Mancini ${ }^{\mathrm{a}}$, Margarita Parra $^{\mathrm{b}, \mathrm{c}}$, Salvador Gil ${ }^{\mathrm{b}, \mathrm{c}}$, Ana M. Costero ${ }^{\mathrm{b}, \mathrm{c}}$

${ }^{a} I Q A L$ (UNL-CONICET), Laboratorio Fester-QUIMICA ORGANICA (FIQ), Universidad Nacional del Litoral, 3000 Santa Fe, Argentina ${ }^{b}$ Centro de reconocimiento Molecular y Desarrollo Tecnológico (IDM), Unidad Mixta Universidad Politécnica de Valencia-Universitat de Valencia, Spain. ${ }^{~}$ Departamento de Quimica Orgánica, Universitat de Valencia, Dr. Moliner, 50, 46100 Buyjassot (Valencia), Spain.

Abstract: A new fluorogenic and chromogenic probe (L) for the selective, sensitive and naked-eye detection of $\mathrm{Cu}^{2+}$ is reported. Complexation constant, complex stoichiometry and quantum chemical (DFT) calculation for $\mathrm{Cu}^{2+}$ complex has been determined. Also, detection limits and the selectivity in front of other divalent and trivalent cations have been evaluated.

Keywords: Chemosensor, Copper ion (II), Fluorescence, Chromophore, UV-Vis, DFT

\section{INTRODUCTION}

The design and synthesis of chemosensors for transition and p-block metal cations is an important subject in the field of supramolecular chemistry because of their impact in the environment and in human health. ${ }^{[1]}$

Divalent cations have important biological properties. Copper is the third most abundant ion in our body and is essential to the proper functioning of metabolic processes. ${ }^{[2]}$ Nevertheless, its presence in abundant quantities causes poisoning in humans or plants and problems in surface waters. ${ }^{[3]}$

The detection of these type of cations presents a grown interest in the field of supramolecular and coordination chemistry because their presence in biologic process, in medicine and the environmental. ${ }^{[4]}{ }^{[5]}$ Biological sensors are usually very selective but very sensitive to changes of $\mathrm{pH}$, temperature, redox potential, etc. Due to these facts, the design and synthesis of new more stable artificial sensors has a huge urgency.

In the last century analytical techniques to determine ions has improved, but most of these methods require expensive equipment and often the presence of other cations interferes. ${ }^{[6]}$ Thus, a sensitive, more selective and simpler analytical method is an urgent need.

In this work we decided to employ 5,5'-bis-vanillin as a dialdehyde which is prepared from the monomeric vanillin by an oxidative coupling. It has been reported that some biphenyl sensors can suffer changes in the colorimetric or fluorescence properties as a result of the modification in the dihedral angle between both aromatic rings, which render possible the recognition of certain cations. ${ }^{[7][8][9]}$

*Address correspondence to this author at the, Facultad de Ingeniería Quimica Universidad Nacional del Litoral, Santiago del Estero 2829, 3000, Quimica, Universil: Santa Fe, Argentina;

mkneeteman@fiq.unl.edu.ar
The carbonyl groups can be functionalized in conventional form giving a byphenyl hydrazone $(\mathrm{L}) .^{[10]}$ The use of hydrazones in detecting metal cations, anions and neutral molecules has been extensively studied. ${ }^{[11][12]}$

The simple and high-yielding synthetic methods employed for the preparation of these compounds are especially attractive.

Recently we informed on several bis-vanillin derivatives containing semicarbazone moieties which have been prepared and used in discriminating trivalent cations. The prepared probes are readily obtained and they are usually highly crystalline. ${ }^{[13]}$

Taking into consideration that the changes in the dihedral angle on byphenyl structures products of the interaction with metal cations can be used for the recognition of the metal, the aim of the present study is to explore sensor capacity and sensitivity of a benzothiazole hydrazone derivative from $5,5^{\prime}$-bis-vanillin to examine $\mathrm{Cu}^{2+}$ in front of other cations using colorimetric and fluorimetric methods. Moreover, the structure, geometry and stability of the $\mathrm{Cu}^{2+}$ complex can be probed by density functional theory (DFT) based quantum chemical calculations.

\section{RESULTS AND DISCUSSION}

\subsection{Synthesis and characterization of ligand $L$}

The ligand $\mathrm{L}$ was prepared using a conventional process. 5,5 '-bis-vanillin was obtained with excellent yield after precipitation $(95 \%)$ from the oxidative coupling of vanillin with sodium persulphate and iron sulphate by a reported procedure. ${ }^{[14]}$

Ligand $\mathrm{L}$ was synthesized as described in Scheme 1. Then was isolated by filtration and purified by recrystallization. Its ${ }^{1} \mathrm{H}$ NMR, ${ }^{13} \mathrm{C}$ NMR and MS ${ }^{[15]}$ spectroscopic data were consistent with those reported in the literature. ${ }^{[3]}$

The UV-vis spectrum of $\mathrm{L}(10 \mu \mathrm{M})$ in DMSO solution exhibits two bands at 257 and $360 \mathrm{~nm}$ with $\varepsilon=127000$ and 
In order to determinate the binding stoichiometry of the $\mathrm{L}-\mathrm{Cu}^{2+}$ complex, the titration profile (Fig. 3.b) was fitted nicely a $1: 1$ binding model using the following equation, where $A$ is the absorbance of the solution during the titration, $A_{\text {lim }}$ is the absorbance of the complex, $A_{o}$ is the absorbance of the free ligand, $C_{o}$ and $C_{M}$ ligand and metal concentration during titration, respectively and $K$ is the complexation constant. ${ }^{[19]}$

$\mathrm{A}=\mathrm{A}_{o}+\left[\left(A_{\text {lim }}-A_{o}\right) / 2 C_{o}\right]\left[C_{o}+C_{M}+K^{-1}-\sqrt{\left(C_{0}+C_{M}+K^{-1}\right)^{2}-4 C_{o} C_{M}}\right]$

The complexation constant was obtained to be $\log \mathrm{K}$ $=5.17 \pm 0.06\left(\mathrm{r}^{2}=0.96\right)$ in a DMSO-acetonitrile solution. The limit of detection (LOD) was also evaluated based on the UV-vis titration from the equation: $L O D=3 \mathrm{Sb} / \mathrm{S}$, where $S b$ is the standard deviation of the blank and $S$ is the slope of the calibration curve. ${ }^{[20]}$ Thus, the calculated detection limit was $1.47 \mu \mathrm{M}$ (see Supplementary data). ${ }^{[21]}$

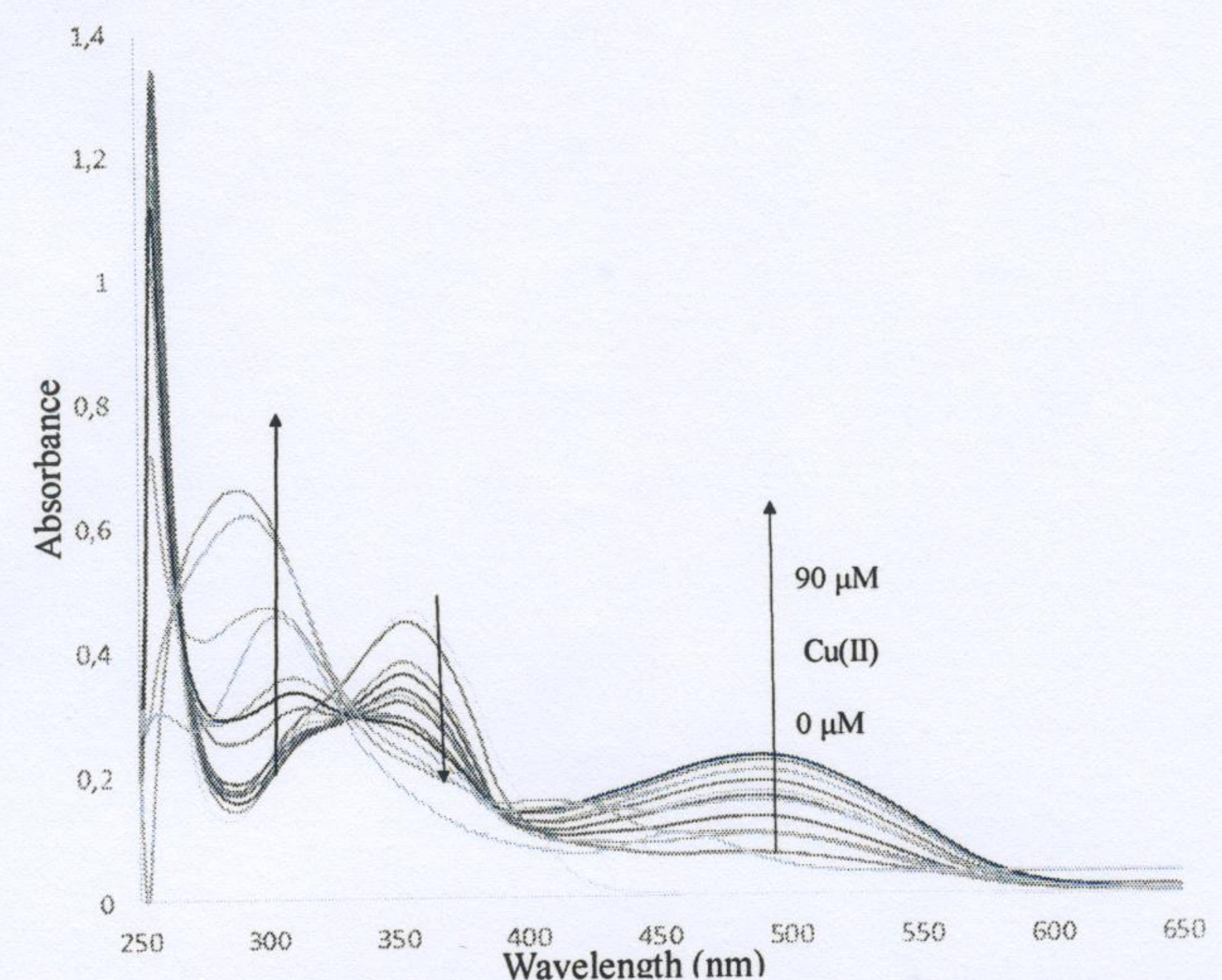

Figure 3.a. UV-vis titration spectra of $\mathbf{L}(10 \mu \mathrm{M}$ DMSO) when different amount of $\mathrm{Cu}^{2+}$ were added.

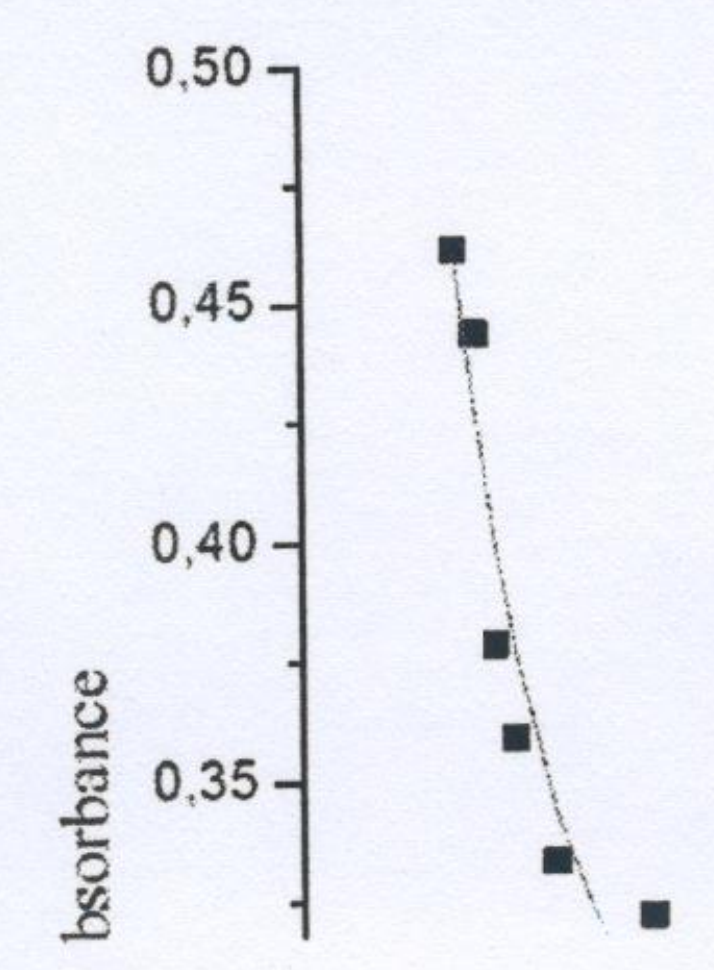

The ${ }^{1} \mathrm{H}$ NMR spectra of $\mathrm{L}$ in the presence and absence of $\mathrm{Cu}^{2+}$ were also investigated to further elucidate the mode of interaction between $\mathrm{Cu}^{2+}$ and $\mathrm{L}$ and conformation changes (Fig. 4). The peak at 3.37 $\mathrm{ppm}$ was attributable to the protons of the methoxy groups, which after the addition of 1 equiv of $\mathrm{Cu}^{2+}$ in a DMSO-d6: $\mathrm{D}_{2} \mathrm{O}(1: 1 \mathrm{v} / \mathrm{v})$ solution, displayed an downfield shift $(\Delta \delta=1.13 \mathrm{ppm})$ and broadened because of the paramagnetic nature of the cation. ${ }^{[2]} \mathrm{A}$ conformational change in the ligand as a consequence of the coordination with $\mathrm{Cu}^{2+}$ could explain the shifts of the methoxy signals. In addition, for further inspection of the binding mode, quantum chemical DFT calculation of the structure of $\mathrm{L}$ was performed. ${ }^{[23]}$

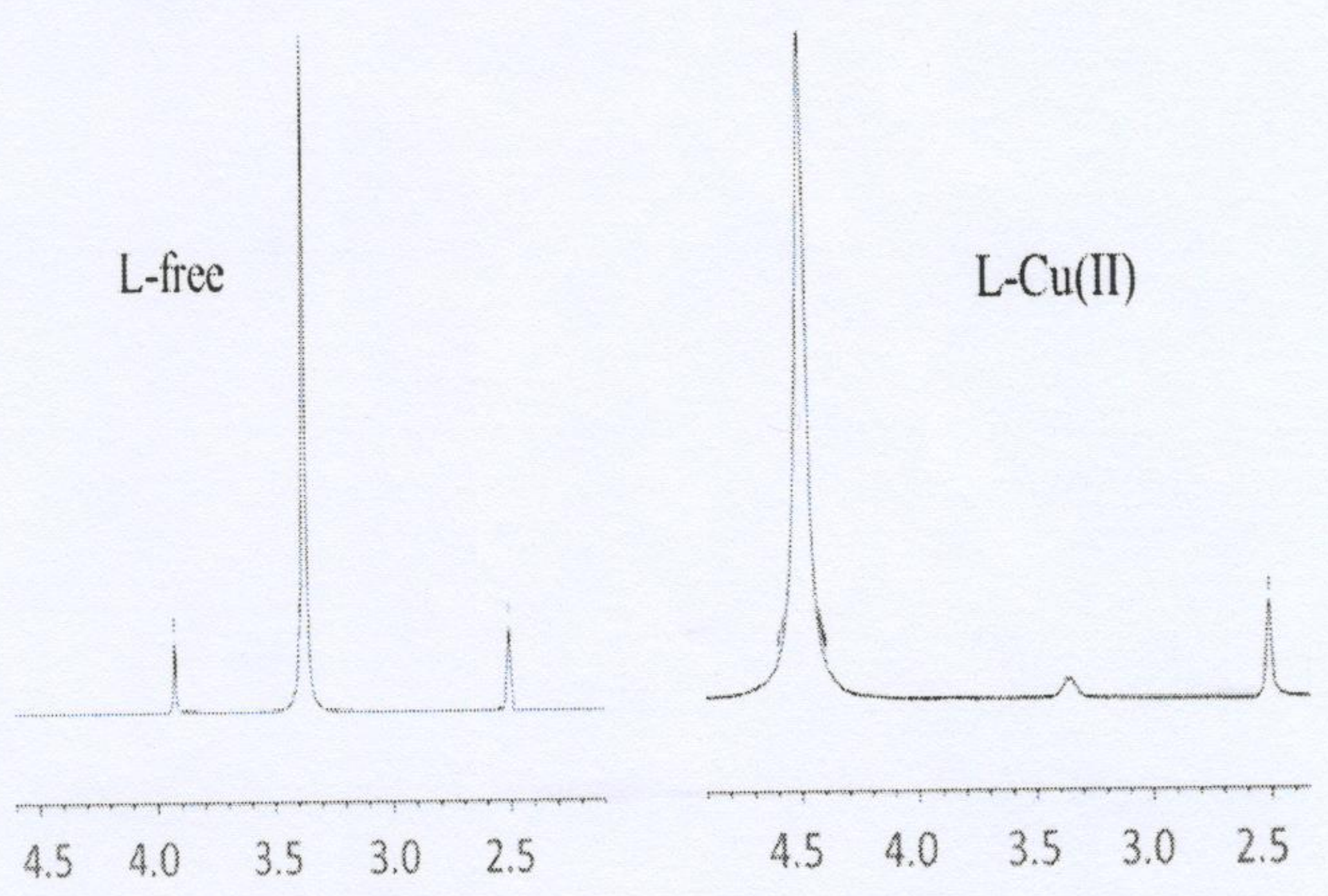

Figure 4. ${ }^{1} \mathrm{H}$ NMR spectra of $\mathrm{L}$ (in DMSO- $\mathrm{d}_{6}$ ) and $\mathrm{L}-\mathrm{Cu}^{2+}$ (DMSO- $\mathrm{d}_{6}: \mathrm{D}_{2} \mathrm{O} 1: 1$ ) and fitting to $1: 1$ complex model.

Optimized geometries of $\mathrm{L}$ and $\mathrm{L}_{-} \mathrm{Cu}^{2+}$ are shown in Fig. 5. From these geometry optimizations, the values of the dihedral angle between benzene rings were obtained.

The dihedral angle for $\mathrm{L}$ and $\mathrm{L}-\mathrm{Cu}^{2+}$ are $59,53^{\circ}$ and $48,41^{\circ}$, respectively. These results demonstrate that the dihedral angle decreases $\left(\sim 11^{\circ}\right)$ as a consequence of $\mathrm{L}$ chelation with $\mathrm{Cu}^{2+}$, increasing the conformational rigidity of the ligand. This can be responsible for the bathochromic shift of $\mathrm{L}-\mathrm{Cu}^{2+}$ in the UV-vis spectra and it also can be responsible of the enhanced fluorescence intensity of this complex. ${ }^{[24]}$ It is found that $\mathrm{Cu}^{2+}$ is coordinated to both $-\mathrm{N}$ sites of benzothiazoles as shown in Fig. 5.b. The $\mathrm{Cu}^{2+}-\mathrm{N}$ bond 
$35765 \mathrm{~cm}^{-1} \mathrm{M}^{-1}$, respectively. DMSO was the only solvent that allowed complete solubilization of $\mathrm{L}$. This large value of molar extinction coefficient would indicate the absorption is due to the $\pi \rightarrow \pi^{*}$ transition of the benzene ring. On the other hand, $\mathrm{L}$ shows an emission band at $327 \mathrm{~nm}$ under excitation at $280 \mathrm{~nm}$. However, its fluorescence quantum yield is low $\left(\phi_{\mathrm{F}} \sim 0.015, \lambda_{\text {exc }}=278 \mathrm{~nm}\right.$ calculated by comparing with rhodamine $\mathrm{B}$ as patron). ${ }^{[16]}$<smiles>COc1cc(C=O)ccc1O</smiles>

Scheme 1. Synthesis of L.

\subsection{Sensing experiments}

Selectivity is a fundamental parameter to determine the viability of a chemosensor. ${ }^{[17]}$ To evaluate the selectivity of $\mathrm{L}$ for $\mathrm{Cu}^{2+}$, the sensing ability of $\mathrm{L}(10 \mu \mathrm{M}$ DMSO) toward different cations $\left(\mathrm{Mn}^{2+}, \mathrm{Sn}^{2+}, \mathrm{Zn}^{2+}, \mathrm{Cu}^{2+}, \mathrm{Fe}^{3+}, \mathrm{Cr}^{3+}\right.$ and $\left.\mathrm{Al}^{3+}\right)$ as their chloride and nitrate salts were studied using UV-vis spectroscopy. ${ }^{[18]}$ The selective and instant detection of $\mathrm{Cu}^{2+}$ by $\mathrm{L}$ was also observed by the naked eye. Initially, the solution of $\mathrm{L}$ was colorless and after addition of 1 equiv of $\mathrm{Cu}^{2+}$, the solution showed an instantaneous color change from colorless to strong red (Fig. 1, inset). It is necessary taken into account that the cooper salt in solution shown a $\mathrm{UV}$ band to $460 \mathrm{~nm}$. Whereas, other cations did not show any notable response.

As shown in Fig. 1, upon addition of 1 equiv of $\mathrm{Cu}^{2+}$, the absorption band of $\mathrm{L}$ at $360 \mathrm{~nm}$ gradually decreased and shifted to a new band at $490 \mathrm{~nm}$. These results demonstrate that $\mathrm{L}$ can serve as an excellent selective chromogenic chemosensor for $\mathrm{Cu}^{2+}$.

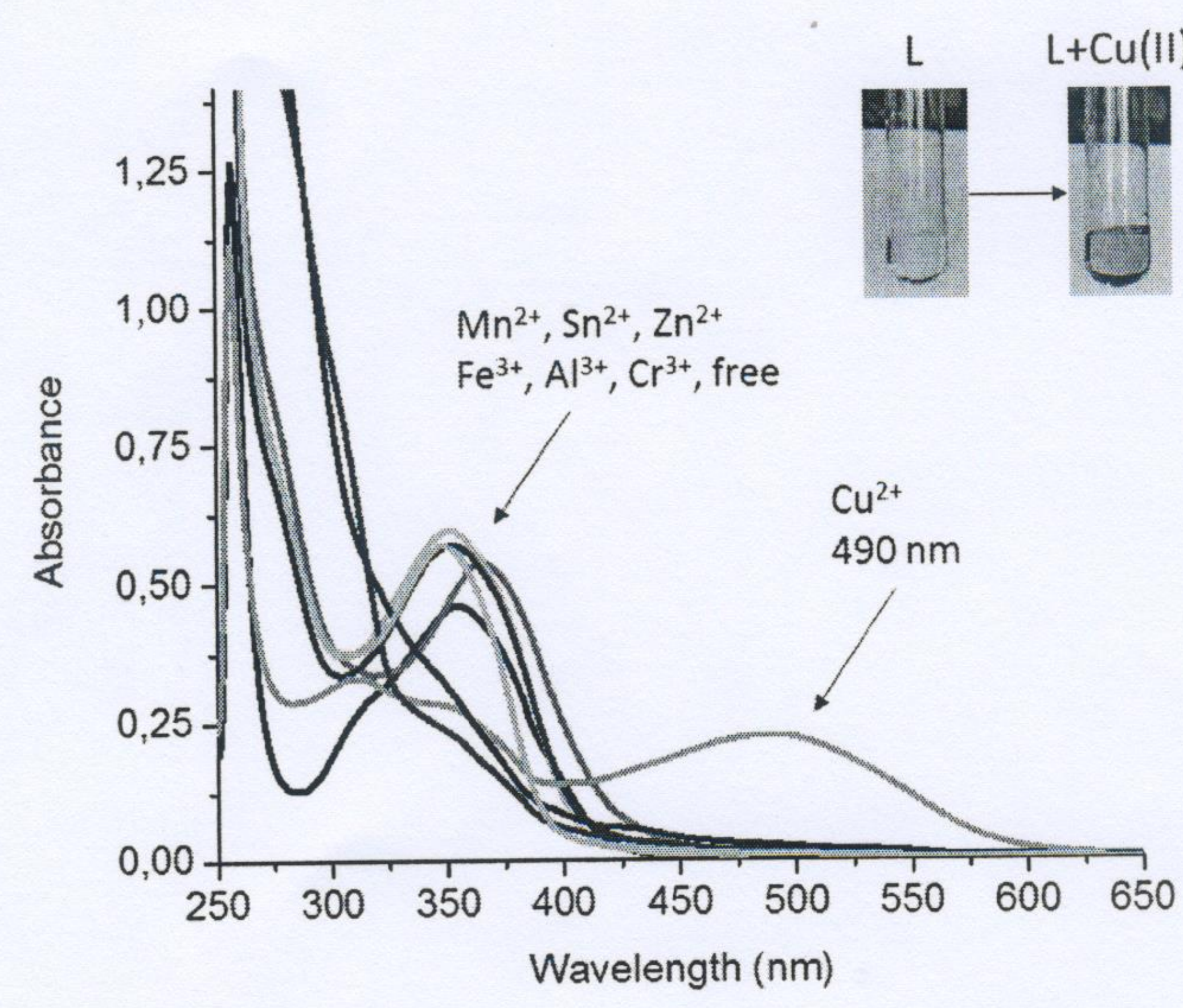

Figure 1. UV-vis absorption spectra of $\mathrm{L}$ with $\mathrm{Cu}^{2+}$ and other metal ions (inset: visual colour change with $\mathrm{Cu}^{2+}$ ).
To explore $\mathrm{L}$ as a fluorescence sensor, fluorescence study was carried out with various cations. When a solution of $\mathrm{Cu}^{2+}$ in acetonitrile was added to the $\mathrm{L}$ solution $(10 \mu \mathrm{M}$, DMSO), the fluorescence emission of $\mathrm{L}$ exhibits a notably fluorescence enhancement. This enhancement is due to the formation of the complex which adopts a molecular disposition consistent with the enhancement, instead the ligand has free rotation and for this reason the phenomenon is lower. In addition, there was a bathochromic shift from $327 \mathrm{~nm}$ to $340 \mathrm{~nm}$ under excitation at $280 \mathrm{~nm}$ upon the addition of different amounts of $\mathrm{Cu}^{2+}$ (Fig. 2).

Fluorescence quantum yields $(\phi)$ of $\mathrm{L}$ and $\mathrm{L}-\mathrm{Cu}^{2+}$ were calculated by comparing the total fluorescence intensity under the whole fluorescence spectral range with that of a standard, according to the next equation:

$$
\phi=\phi_{R} \cdot \frac{1-10^{-A_{R}}}{1-10^{-A}} \cdot \frac{I}{I_{R}} \cdot \frac{n^{2}}{n_{R}^{2}}
$$

Where $\phi_{R}$ is the quantum yield of rhodamine $\mathrm{B}=0.44$ (DMSO, $\left.1.10^{-5} \mathrm{M}\right), I$ and $I_{R}$ are the total fluorescence intensity under whole fluorescence spectral curve, $A$ and $A_{R}$ are the optical density of the sample and standard, and $n$ is the refractive index of the solvent at $293 \mathrm{~K}$.

The calculated fluorescence quantum yield for $\mathrm{L}-\mathrm{Cu}^{2+}$ with respect to rhodamine B was 0.70 , an increase of $4000 \%$ respect of $\mathrm{L}$. The other metal ions studied did not show fluorescence increment under the same conditions. All the above results demonstrate the utility of $\mathrm{L}$ to be used as a chemosensor for $\mathrm{Cu}^{2+}$ by the colorimetric and fluorescence dual mode.

Due to the strong effect observed with $\mathrm{Cu}^{2+}$, the complexation characteristics of $\mathrm{L}$ were studied. Thus, $\mathrm{Cu}^{2+}$ titration experiments against $\mathrm{L}$ in DMSO were monitored using UV-vis spectroscopy. The absorption spectra of $\mathrm{L}(10 \mu \mathrm{M})$ in DMSO solution upon addition of $\mathrm{Cu}^{2+}$ aliquots is shown in Fig. 3.a. The original band at $360 \mathrm{~nm}$ showed a decrease in absorption with the increase of $\mathrm{Cu}^{2+}$ concentration while two new bands at 290 and $490 \mathrm{~nm}$ increased progressively. Moreover, two isosbestic points were observed at 330 and $400 \mathrm{~nm}$, which would indicate the presence of a single coordination equilibrium between $\mathrm{L}$ and $\mathrm{Cu}^{2+}$. 
length value is $1,88 \AA$ and $1,89 \AA$ for each $-\mathrm{N}$. The total energy of optimized structures of $\mathrm{L}$ and $\mathrm{L}-\mathrm{Cu}^{2+}$ are 2582,74 and $-4222,76$ Hartree, respectively. The optimization energy values suggest that the total energy of the complex was lower compared to $\mathrm{L}$ indicating higher stability of the $\mathrm{L}-\mathrm{Cu}^{2+}$ complex.

To understand the electrical transport properties, HOMO-LUMO gap of $\mathrm{L}$ and $\mathrm{L}-\mathrm{Cu}^{2+}$ have been also estimated using the same DFT method. The negative energy values for HOMO and LUMO in L and in L$\mathrm{Cu}^{2+}$ signifies that both molecules are stable. The energy gaps between the HOMO and LUMO $\left(\Delta \mathrm{E}_{\mathrm{H}-\mathrm{L}}\right)$ in $\mathrm{L}$ and $\mathrm{L}-\mathrm{Cu}^{2+}$ are $89,81 \mathrm{Kcal} / \mathrm{mol}$ and $13,51 \mathrm{Kcal} / \mathrm{mol}$ respectively. It shows that the complexation decreases the HOMO-LUMO energy gap, stabilizing the system. It also suggested the process of electron transfer from electron rich $\mathrm{L}$ to electron deficient $\mathrm{Cu}^{2+}$.



Figure 5. Optimized structures of $\mathrm{L}$ (a) and $\mathrm{L}-\mathrm{Cu}^{2+}$ complex (b). The dihedral angle for $\mathrm{L}$ and $\mathrm{L}$ $\mathrm{Cu}^{2+}$ are $59,53^{\circ}$ and $48,41^{\circ}$, respectively.

\section{CONCLUSIONS}

In summary, a new highly selective and sensitive chemosensor has been prepared in an easy way from a bisvanillin derivative. It can be utilized for the naked-eye detection of $\mathrm{Cu}^{2+}$. It was also shown the probe's selectivity even in the presence of other metal cations through UV-Vis and fluorescence spectroscopies.

Additionaly, through a theoretical study using DFT calculations with the B3LYP method and 6-31G(d,p) set of basis functions, we propose a model of complex between $\mathrm{L}$ and $\mathrm{Cu} 2+$ with $1: 1$ stoichiometry. It was interesting that coordination with the metal occurs through the nitrogen atoms of the heterocyclic moiety of the corresponding hydrazone.
This research was supported by the Agencia Nacional de Ciencia y Tecnología (ANCyT) of Argentina -PICT 2014 No. 1587 and by the Universidad Nacional del Litoral, Santa $\mathrm{Fe}$, Argentina.

\section{REFERENCES}

[1] Zhao, Q.; Li, F.; Huang, C. Phosphorescent chemosensors based on heavy-metal complexes. Chem. Soc. Rev. 2010, 39, 3007; Tsukanov, A. V.; Dubonosov A.D.; Bren, V.A.; Minkin V.-I. Organic chemosensor with crown-ether groups. Chem. Heterocycl. Compd. 2008, 44, 899; Prodi, L.; Balleta, F.; Mantalti, M.; Zaccheroni, N. Luminiscnt chemosensors for transition metal ions. Coord. Chem. Rev. 2000, 205, 59 .

[2] Mathie, A; Sutton, G. L; Clarke, C. E; Veale, E. L. Zinc and copper Pharmacological probes and endogenous modulators of neuronal excitability. Pharm. Ther. 2006, 111, 567.

[3] Gaetke, L. M; Chow, C. K. Copper toxicity, oxidative stress, and antioxidant nutrients. Toxicology 2003, 189, 147.

[4] Suganya, S; Velmathi, S; Mubarak Ali, D. Highly selective chemosensor for nano molar detection of $\mathrm{Cu} 2+$ ion by fluorescent turn-on response and its application in living cells. Dyes Pigm. 2014, 104,116 
[5] Prodi, L; Bolletta, F; Mantalti, M; Zaccheroni, N. Luminescent chemosensors for transition metal ions. Coord. Chem. Rev. 2000, 205, 59.

[6] Wang, S; Cong, T; Liang, Q; Li, Z; Xu, S. Dual colorimetric and fluorescent chemosensor of $\mathrm{Fe}^{3+}$ and $\mathrm{Cu}^{2+}$ based on 2,5-bis[(4carboxylic-piperidylamino) thiophenyl]- croconine. Tetrahedron, 2015, 7, 5478 .

[7] Bravo, V; Gil, S; Costero, A. M; Kneeteman, M. N; Llaosa. U; Mancini, P. M. E; Ochando, L. E; Parra, M. A new phenanthrenebased bis-oxime chemosensor for $\mathrm{Fe}(\mathrm{III})$ and $\mathrm{Cr}$ (III) discrimination. Tetrahedron, 2012, 68, 4882.

[8] Costero, A. M; Bañuls, M. J; Aurell, M. J; Ochando, L. E; Doménech, A. Cation and anion fluorescent and electrochemical sensors derived from 4,40 -substituted biphenyl. Tetrahedron, 2005, 61, 10309.

[9] Costero, A. M; Bañuls, M. J; Aurell, M. J; Doménech, A. 4,4'Substituted biphenyl coronands. Preparation of a new selective fluorescent sensor for mercury salts. Tetrahedron, 2006, 62, 11972.

[10] General procedure to L. 5,5'-Bis-vanillin $(0.66 \mathrm{mmol})$ was suspended in absolute ethanol $(30 \mathrm{ml})$ and 2-hydrazinylbenzothiazole (1.32 $\mathrm{mmol}$ ) was added to the suspension. The reaction mixture was refluxed for 4 days. At the beginning of the heating all product is dissolved and over time it begins to appear a new precipitate. The solid was filtered and dried to give a pure solid.

5,5'-bis-vanillin: Yield: $75 \%, \mathrm{mp}>270{ }^{\circ} \mathrm{C}$. ${ }^{1} \mathrm{H}$ NMR (DMSO- $\mathrm{d}_{6}$, $300 \mathrm{MHz}): 3.83\left(\mathrm{~s}, 6 \mathrm{H}, \mathrm{OCH}_{3}\right) ; 7.36(\mathrm{~d}, 2 \mathrm{H}, \mathrm{CAr}-\mathrm{H}) ; 7.32$ (d, $2 \mathrm{H}, \mathrm{CAr}-\mathrm{H}$ ) 9.71 (s, 2H, CHO). ${ }^{13} \mathrm{C}$ NMR (DMSO-d, 300 $\mathrm{MHz}$ ) 192 (CHO); 148 (C-4); 129 (C-6); 128 (C-1); 125 (C-5); $110(\mathrm{C}-2)$. IR ( $\left.\mathrm{KBr}, \mathrm{cm}^{-1}\right): 3264.2(\mathrm{OH}) ; 1674.2(\mathrm{C}=\mathrm{O}) ; 1587.4$ (C=C Arom.). L: Yield: $75 \%, \mathrm{mp}>270{ }^{\circ} \mathrm{C}$. ${ }^{1} \mathrm{H}$ NMR (DMSO-d $300 \mathrm{MHz}$ ): 12.10 (s, 2H, NH); 9.00 (br. s, 2H, OH); 8.08 (s, 2H, $\mathrm{CH}=\mathrm{N}) ; 7.72\left(\mathrm{~d}, 2 \mathrm{H}, \mathrm{J}=8 \mathrm{~Hz}, \mathrm{H}-6^{\prime}\right) ; 7.40$ (d, $\left.2 \mathrm{H}, \mathrm{J}=8 \mathrm{~Hz}, \mathrm{H}-3^{\prime}\right)$ 7.31 (s, 2H, H-6); 7.29 (t, 2H, J=8 Hz, H-4'); 7.13 (s, 2H, H-2); $7.09\left(\mathrm{t}, 2 \mathrm{H}, \mathrm{J}=8 \mathrm{~Hz}, \mathrm{H}-5\right.$ '); $3.93\left(\mathrm{~s}, 6 \mathrm{H}, \mathrm{OCH}_{3}\right) .{ }^{13} \mathrm{C} \mathrm{NMR}$ (DMSO-d 6,300 MHz): 167 (C-1'); 150 (C-3); 148 (C-4); 146 $(\mathrm{CH}=\mathrm{N}) ; 127$ (C-2' and C-7'); $126(\mathrm{C}-1) ; 125$ (C-5); 123 (C-3' and $\mathrm{C}-6$ '); $122(\mathrm{C}-6) ; 121\left(\mathrm{C}-2^{\prime}\right) ; 109(\mathrm{C}-2) ; 56\left(\mathrm{OCH}_{3}\right)$. HRMS calcd for $\mathrm{C}_{30} \mathrm{H}_{24} \mathrm{~N}_{6} \mathrm{O}_{4} \mathrm{~S}_{2} 596.1300$ found $(\mathrm{M}+1): 597.1379$

[11] Xu, H; Wang, X; Zhang, C; Liu, Z. Coumarin-hydrazone based high selective fluorescence sensor for copper(II) detection in aqueous solution. Inorg. Chem. Commun.,2013, 34, 8.

[12] Kumari, C; Sain, D; Kumar, A; Nayek, H. P; Debnath, S; Dey, S. A bis-hydrazone derivative of 2,5-furandicarboxaldehyde with perfect hetero-atomic cavity for selective sensing of $\mathrm{Hg}(\mathrm{II})$ and its intracellular detection in living HeLa S3 cell. Sens. Actuators, A., 2017, 243, 1181

[13] Costero, A. M; Gil, S; Parra, M; Mancini, P. M. E; Kneeteman, M. N; Quindt, M. I. 5,5'-Bis-vanillin derivatives as discriminating sensors for trivalent cations. Tetrahedron Letters, 2015, 56, 3988

[14] Elbs, K; Lerch, H. Über dehydrodivanillin J. Prakt. Chem. (Weinheim, Ger.), 1916, 93, 1
[15] General methods: the different materials were purchased and used as received. Silica gel 60 F254 (Merck) plates were used for TLC. ${ }^{1} \mathrm{H}$ and ${ }^{13} \mathrm{C}$ NMR spectra were recorded using a Bruker DRX-500 spectrometer $(300 \mathrm{MHz})$ with the deuterated solvent as the lock and residual solvent as the internal reference. HRMS were recorded using a Shimadzu QP5050A. Absorption spectra were recorded with a Perkin Elmer Lambda 20 spectrophotometer. Fluorescence spectra were carried out in a Hitachi F-7000 fluorimeter. 5,5'-bis-vanillin was prepared following the procedure described in Ref. [9]

[16] Singh, T. S; Mitra, S; Chandra, A. K; Tamai, N; Kar, S. A combined experimental and theoretical study on photoinduced intramolecular charge transfer in trans-ethyl p-(dimethylamino)cinamate. $J$. Photochem. Photobiol. A: Chem., 2008, 197, 295.

[17] Li, W.-F; Ma, H.-C; Lu, C; Ma, Y; Qi, C.-X; Zhang, Z.-W; Yang, Z.M; Cao, H.-Y; Lei, Z.-Q. A self-assembled triphenylamine-based fluorescent chemosensor for selective detection of $\mathrm{Fe} 3+$ and $\mathrm{Cu} 2+$ ions in aqueous solution. RSC $A d v$., 2015, 5, 6869 .

[18] Spectroscopic Measurements. Metal cations $\left(\mathrm{Mn}^{2+}, \mathrm{Sn}^{2+}, \mathrm{Zn}^{2+}, \mathrm{Cu}^{2+}\right.$ $\left.\mathrm{Fe}^{3+}, \mathrm{Cr}^{3+}, \mathrm{Al}^{3+}\right)$ as nitrate or chloride salts were used to obtain solutions of concentration of $10^{-5} \mathrm{M}$ in $\mathrm{MeOH}$ or acetonitrile. UV-Vis spectra were recorded using a Perkin Elmer Lambda 20 spectrometer. Fluorescence spectra were recorded using a Hitachi F-7000 fluorometer. Titrations were performed by adding aliquots of different salts (in $\mathrm{CH}_{3} \mathrm{CN}$ ) in a solution of $\mathbf{L}\left(10^{-5} \mathrm{M}\right)$ in DMSO.

[19] Bourson, J; Pouget, J; Valeur, B. Ion-responsive fluorescent compounds. 4. Effect of cation binding on the photophysical properties of a coumarin linked to monoaza- and diaza-crown ethers. J. Phys. Chem., 1993, 97, 4552.

[20] Zhu, M; Yuan, M; Liu, X; Xu, J; Lv, J; Huang, C; Liu, H; Li, Y; Wang, S; Zhu, D. Visible near-infrared chemosensor for mercury ion Org. Lett., 2008, 10, 1481 .

[21] General procedure for limit of detection determination. Increasing amounts of $\mathrm{Cu}^{2+}$ solutions (in acetonitrile) were added to $\mathrm{L}$ in DMSO $\left(10^{-5} \mathrm{M}\right)$. The UV spectra were recorded in $1 \mathrm{~cm}$ path length cells at 25 ${ }^{\circ} \mathrm{C}$ (thermostated). The representation of absorbance at $380 \mathrm{~nm}$ vs. concentration of $\mathrm{Cu}^{2+}$ allowed the limit of detection to be calculated.

[22] Rathinam, B; Chien, C. C; Chen, B.-C; Liu, J.-H; Fluorogenic and chromogenic detection of $\mathrm{Cu}^{2+}$ and $\mathrm{Fe}^{3+}$ species in aqueous media by rhodamine-triazole conjugate. Tetrahedron, 2013, 69, 235.

[23] Computational details. The calculations were performed with Gaussian 09 program using DFT level of theory. Geometry optimizations and vibrational frequencies of $\mathrm{L} 5$ and $\mathrm{L} 5-\mathrm{Cu}^{2+}$ were calculated with B3LYP (Becke's three parameter nonlocal hybrid Exchange-correlation functional) modeling method and 6-31G(d,p) set of basis functions. Frontier molecular orbitals (FMO) have been also estimated by same DFT method to show continuous charge distributions and reactive sites of the molecules.

[24] Sanjoy, Singh T; Pradip, C. P; Pramanik, H. A. R. Fluorescent chemosensor based on sensitive Schiff base for selective detection of $\mathrm{Zn}^{2+}$. Spectrochim. Acta, Part A; 2014, 121, 520. 